\title{
Sustainability of Feed-based Aquaculture in Bangladesh ${ }^{50}$
}

\author{
Md. Rais Uddin Mian*
}

\begin{abstract}
Six carp and carp based culture technologies were selected to examine the sustainability of supplementary feed-based aquaculture through availability of domestic feeds compared to the total requirement in Bangladesh. The study covered seven districts of Bangladesh with a sample size of 376. It was found that farmers used a good number of feeds (more than 35) for the selected technologies but they maintained no standard doses for them. There were important differences among the prices of different feeds and other inputs used for different technologies in different parts of the country. Prices of all inputs were found to be increasing and this increase has been greater in recent years as compared to previous years. Though all the technologies were found to be profitable, the feed situation was not satisfactory. Except for rice polish, the supplies of other local feeds were unable to meet the national demand. If this situation persists and no measures are taken to secure the local feed supply, the present development of supplementary feed-based aquaculture will become dependent on imported feeds and would not be sustainable in the future. This study strongly suggests that the authorities should handle the matter with proper attention, considering its significant impact in the economy of the country.
\end{abstract}

Keywords: Profitability, Composition, Availability, Sustainability

\section{Introduction}

Fish and fisheries have been an integral part of the life of the people of Bangladesh from time immemorial. This sector contributes about 6 percent of GDP, 16 percent of gross agricultural product and

\footnotetext{
50 The author properly acknowledges the Development of Sustainable Aquaculture Project (DSAP) of USAID for funding the project through WorldFish Centre- Bangladesh and South Asia Office, Dhaka.

* Assistant Professor, Department of Agricultural Finance, Bangladesh Agricultural University, Mymensingh-2202, Bangladesh.
} 
about Tk. 20 billion (10 percent) of export earnings, of which frozen shrimp constitutes 82 percent while the rest are fish and other aquatic products (BBS, 2000). Total fish production in Bangladesh in 1998-99 was reported to be 1.552 million metric tons (MT) of which 0.65 million MT (42 percent) was from inland open waters, 0.593 million MT ( 38 percent) from inland closed waters and 0.309 million MT (20 percent) from marine fisheries. The largest three contributors to total inland production (including capture and culture) are ponds (32 percent), flood lands (26 percent) and rivers and estuaries (10 percent). The overall growth rate of fish production of Bangladesh for the period 1984-85 to 1997-98 was 5.02 percent. These figures display several important features. First, although inland open water fisheries are still the largest contributors to total fish production, their share has declined from 62 percent in 1983-84 (471,595 MT) to only 42 percent $(649,418 \mathrm{MT})$ in $1998-99$, while the contribution from inland closed waters (culture) fisheries has increased from 16 percent $(117,025 \mathrm{MT})$ in $1983-84$ to 38 percent $(593,202 \mathrm{MT})$ in $1998-99$. During this period, the share of marine fisheries fell from 24 to 20 percent. Almost all the growth of culture fisheries occurred since 1989-90; and since then, total production nearly doubled by 1997-98, led by aquaculture in inland closed waters which increased output at a remarkable rate of 13 percent per year (BBS, 2004). As the contribution of inland open water fisheries is declining and the contribution of marine fisheries is growing slowly, it is necessary to think of culture fisheries as the appropriate means to increase fish production for the growing population.

Culture fisheries have already shown their dominance in total fish production over the last 15 years or so. Pond fish farming, shrimp farming and culture-based baors are now the most promising sources for additional fish production. Thus its potential has to be utilized. In fish farming and shrimp/golda farming, pangus farming, cage and pen farming, the use of supplementary feed is very important as far as the achievement of full potential yield is concerned. Supplementary feed is also being used in carp poly cultures by many promising fish farmers and entrepreneurs. Those using supplementary feed produce higher yields per hectare. The Government of Bangladesh and the Department of Fisheries (DoF) are also encouraging fish farming. New agricultural lands are now being converted into fish ponds. Cage and pen cultures are also being encouraged to increase the country's fish production.

The interest in increasing aquaculture yields has necessarily turned attention to the use of supplemental or complete feeds to enhance production. But imported feed ingredients are too expensive and demanding 
of scarce foreign exchange to be practical in Bangladesh. Though the farmers use their feeds economically (especially high valued imported feeds) they are anxious about feed prices and feed availability. Various small-scale local feed milling has been attempted with some promising results but no comprehensive study has been done regarding the availability of local ingredients, their costs and returns as required to support expanded feedbased aquaculture production systems.

Some studies related to this research are Islam and Dewan (1986), Islam (1987), Rahman (1995), Rana (1996), Hossain et al. (1997), Das (2005), Nurunnahar (2005) and Islam (2006). Islam and Dewan (1986) carried out a study on resource use and economic returns in pond fish culture, in which they identified that pond fish production was mainly based on stocking fish seed, use of fertilizer and feed and human labor for different operations and management. They also observed that net return was positively influenced by price of output and economic use of both material inputs and labor. Islam (1987) made efforts to estimate the effects of seven factors on pond fish output using a Cobb-Douglas production function and found that fish seed, fertilizer and artificial feed, human labor, farm size, age of pond and number of pond owners were significant in explaining the variation in pond fish output, but the results varied across the different locations. Rahman (1995) explored the contributions of key variables to the production process of pond fish farming. He observed that ownership of pond, number of species and human labor had a negative impact on pond fish output, while depth of pond water, farm size, fish seed, fertilizer and artificial feed were found to be responsible for explaining the variation in pond fish output. He also identified higher feed prices as one of the major problems of pond fish production in the study area. Rana (1996) worked to find the influencing variables for pond culture and found that pond size and stocking of fingerlings had negative effects and pond ownership, feed, fertilizer and human labor had positive effects on pond fish production. In analyzing the relationship between supplementary feed and fish production, Hossain et al. (1997) showed that the average production of carp of 2133.30 $\mathrm{kg} / \mathrm{ha}$ would be obtained in 105 days in a mixed culture system using supplementary feed (rice bran and mustard oil cake in a ratio of 1:1) at $5 \%$ of total fish body weight daily in two installments. During this research work, the respondents opined that sometimes feeds were not sufficiently available to them and feed prices went beyond their ability to pay. Das (2005) determined the profitability and effects of specific factors on fingerling production under non-government organization (NGO) supervision. She found that producing fingerling in a nursery pond was highly profitable and pond size, cost of spawn stocked, material cost, feed 
cost, human labor cost and management cost had significant impacts on nursery operations. Nurunnahar (2005) observed net return and resource use efficiency of carp poly culture in the Kushtia district of Bangladesh. She found carp poly culture to be a profitable business and other than human labor, inputs were used in an efficient manner. She also found that the poly culture farmers expected higher fish prices as production costs were higher due to higher prices of inputs, especially fish feeds. Islam (2006) worked on the profitability and technical efficiency of hatchery operation and observed hatchery farms to be highly profitable. Education, experience and training received by the hatchery operators were found to be the most important factors explaining technical efficiency.

It is clear that there is no specific study emphasizing sustainability/ feasibility of feed-based aquaculture, especially in Bangladesh. It is in this backdrop that a study on the economics of aquaculture, based on local as well as supplementary feed ingredients, is necessary. Results of this study might be helpful for researchers, extension workers, NGOs and policy makers to make present modern aquaculture as a sustainable means of improving the livelihood of the rural people of Bangladesh.

\section{Objectives of the study}

(i) to determine the profitability of the selected aquaculture technologies using supplementary feeds;

(ii) to examine the compositional variation of fish feeds across different fish farming practices;

(iii) to estimate the demand for, and availability of, local feed ingredients for feed-based aquaculture;

(iv) to study the price movements of local supplementary fish feeds; and

(v) to assess the sustainability of fish culture on the basis of findings of the study for expansion of feed-based future fresh water fish culture. 


\section{Methodology of the Study}

This study used both primary and secondary data to achieve its objectives. Primary data were collected from the fish farmers, fish entrepreneurs (those provided pond and capital but were not directly related), feed manufacturers, feed dealers and feed retailers. The survey collected information on cost, return, price, catch and feed composition of fish culture. On the other hand, secondary data comprised time series information on production of rice, wheat and other mother/original feed produces. Primary data were collected through direct interviews while secondary data were collected from different issues of Bangladesh Bureau of Statistics (BBS) and unpublished but reliable documents of different feed companies. Six fish culture technologies were selected to assess the sustainability of feed-based aquaculture: carp-pangus, carp poly, carp-golda, pangus mono, golda mono and nursery. The sample was selected on the basis of the concentration of farmers where supplementary feed use in aquaculture was relatively widely practiced. On the basis of this criterion, seven districts, i.e., Mymensingh, Bogra, Noakhali, Comilla, Jessore, Khulna and Bagerhat were tentatively selected, from where samples were chosen for the study. Here, carp-pangus and carp-golda imply the simultaneous culture of two fishes in same pond in the same time. On the other hand, pangus mono and golda mono refer to the culture of one fish in one pond only. Moreover, carp poly is the culture of different species of carp and finally nursery refers to fingerling raising ponds. The distribution of the sample is shown in Table-1.

The number of respondents under carp-pangus, carp poly, carpgolda, pangus mono, golda mono and nursery technologies were 55, 100, $65,51,50$ and 55 respectively (Table-1). Thus the total sample size for the study stood at 376. Moreover, the sample respondents were selected from 22 upazilas (sub-districts) comprising four, three, two, one, three, eight and one upazila from Mymensingh, Bogra, Noakhali, Comilla, Jessore, Khulna and Bagerhat respectively. Data were collected for the period of September, 2001 to March, 2002. 
Table-1: Distribution of Samples of the Selected Technologies

\begin{tabular}{ccccccccc}
\hline District & \multicolumn{7}{c}{ Number of respondents/fish farmers } \\
\cline { 2 - 8 } Technology & $\begin{array}{c}\text { Mymen } \\
\text {-singh }\end{array}$ & Bogra & Noakhali Comilla Jessore & Khulna Bagerhat & $\begin{array}{c}\text { All } \\
\text { districts }\end{array}$ \\
\hline Carp-pangus & 33 & 20 & 2 & - & - & - & - & 55 \\
& $(60.00)$ & $(36.36)$ & $(3.64)$ & & & & & $(100)$ \\
Carp poly & 27 & 10 & 30 & 27 & 6 & - & - & 100 \\
& $(27.00)$ & $(10.00)$ & $(30.00)$ & $(27.00)$ & $(6.00)$ & & & $(100)$ \\
Carp-golda & 2 & - & - & - & 25 & 29 & 9 & 65 \\
& $(3.08)$ & & & & $(38.46)$ & $(44.62)$ & $(13.85)$ & $(100)$ \\
Pangus mono & 12 & 39 & - & - & - & - & - & 51 \\
& $(23.53)$ & $(76.47)$ & & & & & & $(100)$ \\
Golda mono & - & - & - & - & 1 & 47 & 2 & 50 \\
& & & & & $(2.00)$ & $(94.00)$ & $(4.00)$ & $(100)$ \\
Nursery & 20 & 12 & - & - & 23 & - & - & 55 \\
& $(36.36)$ & $(21.82)$ & & & $(41.82)$ & & & $(100)$ \\
All & 94 & 81 & 32 & 27 & 55 & 76 & 11 & 376 \\
technologies & $(25.00)$ & $(21.54)$ & $(8.51)$ & $(7.18)$ & $(14.63)$ & $(20.21)$ & $(2.93)$ & $(100)$ \\
Upazila & 4 & 3 & 2 & 1 & 3 & 8 & 1 & 22 \\
surveyed (No.) & $(18.18)$ & $(13.64)$ & $(9.09)$ & $(4.55)$ & $(13.64)$ & $(36.36)$ & $(4.55)$ & $(100)$ \\
\hline
\end{tabular}

Figures within the parentheses indicate percentages of total

Source: Field Survey (2002).

Simple statistical techniques (average, percentage, etc.) were employed to analyze the collected data. Moreover, a moving average technique based on current price was followed to smooth the fluctuations in feed prices and thus examine the price movements of the major local feed items used for the selected fish culture technologies (Puri, 1984).

\section{Result and Discussion}

\subsection{Profitability of the Feed-based Aquaculture}

\subsubsection{Fingerling cost of the selected technologies}

It was found that, except for pangus and golda mono technologies, the others used several types of fingerling for fish culture. Among them carp-golda technology used 10 types while each of the rest used 11 types of fingerling (Table-2). Moreover, in the nursery technology, fingerling was purchased on the basis of both number and weight. Though the selected technologies experienced several fingerling costs, only five major cost items 
of each technology are discussed below. The residual fingerling items constituted minimum shares in total fingerling cost for each of the selected technologies.

In the case of carp-pangus technology, the highest amount of fingerling used was pangus ( 88.12 percent) while it was ruhi (20.24 percent) for carp poly culture and golda $(89.75$ percent) for carp-golda poly culture technologies. In terms of number, the nursery technology used magur fingerling in the highest quantity ( 31.11 percent) and in terms of weight it was the pangus (95.72 percent). The mono culture technologies used only one type of fingerling, i.e., pangus mono culture used pangus fingerling and golda mono culture used golda fingerling only.

In carp-pangus technology, the highest cost was incurred for pangus fingerling (93.46 percent) and it was followed by ruhi ( 2.15 percent), silver carp (1.63 percent), catla (1.48 percent) and silver barb (0.66 percent) fingerlings.

The highest fingerling cost was incurred for ruhi fingerling $(23.81$ percent) for carp poly technology. The second, third, fourth and fifth highest cost for this technology were silver carp (15.79 percent), catla (14.44 percent), mrigel (14.09 percent) and mirror carp (11.97 percent) fingerlings.

Among the 10 species of fingerling used by carp-golda technology, the sequence of the five major fingerling costs was golda, catla, ruhi, grass carp and silver carp with respective shares in total fingerling cost of 94.79, $1.30,1.29,0.81$ and 0.77 percent.

For the nursery technology, pangus contributed the highest cost (65.13 percent) in total fingerling cost (comprising number and weight costs together) followed by magur (12.57 percent), mirror carp (4.62 percent), ruhi $(4.38$ percent) and mrigel (3.48 percent).

In the case of pangus and golda mono culture technologies, where only one type of fish was cultured, fingerling cost for pangus and golda fingerling was Tk. 128602.30 and 57505.26 respectively. 


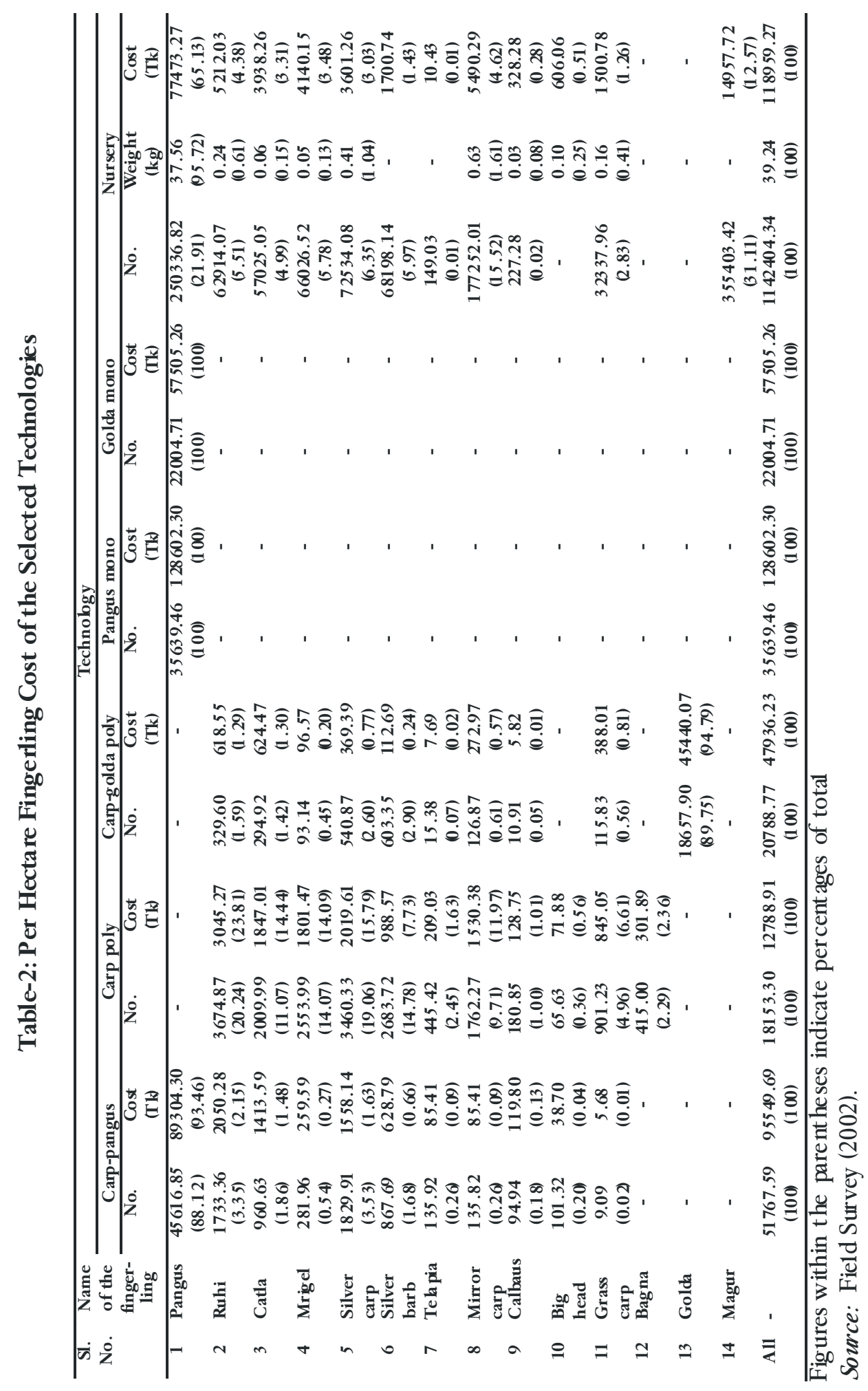




\subsubsection{Feed Cost of the selected technologies}

A huge number of feeds (more than 35) was used for fish production under the selected technologies in the study area, and the farmers followed no standard doses to apply them. Among them the major five feed items (in terms of quantity and cost) are discussed below. The other feed items are excluded from the discussion because of their small shares in total feed amount and cost.

The highest amount of feed used for carp-pangus technology was rice bran ( 24.90 percent) which was followed by wheat bran (16.31 percent), oil cake (12.82 percent), rice polish (8.76 percent) and litter (8.49 percent). But in terms of cost, meat bone ranked the highest ( 16.15 percent) followed by rice bran (15.89 percent), fish meal (14.56 percent), oil cake (12.00 percent) and wheat bran (11.59 percent) (Table-3).

In the case of carp poly technology, the highest feed amount of 26.13 percent was associated with rice polish. The other feed items were oil cake, grass, azola and wheat bran comprising percentages of 16.94, 11.42, 11.37 and 9.14 respectively. On the basis of cost, this order was found to be oil cake, wheat bran, rice polish, rice bran and poultry dropping with respective shares of $40.05,20.12,17.53,10.61$ and 2.59 percent.

Carp-golda technology used mussel meal in the highest amount ( 51.84 percent), while the other feed items were wheat bran $(6.22$ percent), saudi bangla $(6.08$ percent $)$, wheat $(4.07$ percent $)$ and rice polish (3.37 percent). On cost basis, the maximum expenditure was incurred for mussel meal ( 33.76 percent) and was followed by saudi bangla ( 15.23 percent), niribili (7.39 percent), fish meal (6.63 percent) and wheat bran ( 5.74 percent).

In the case of pangus mono technology, the maximum quantity of feed used was rice bran having relative share of 29.57 percent in total feed quantity. The next four feed items were found to be wheat bran, poultry dropping, rice polish and oil cake with their respective shares of 27.81, $24.12,5.67$ and 4.71 percent in total feed quantity. When the feed cost was considered, the order of the five maximum used feed items appeared to be rice bran, wheat bran, meat bone, fish meal and poultry dropping contributing $28.93,28.23,8.91,6.63$ and 6.61 percent in total feed cost respectively. 


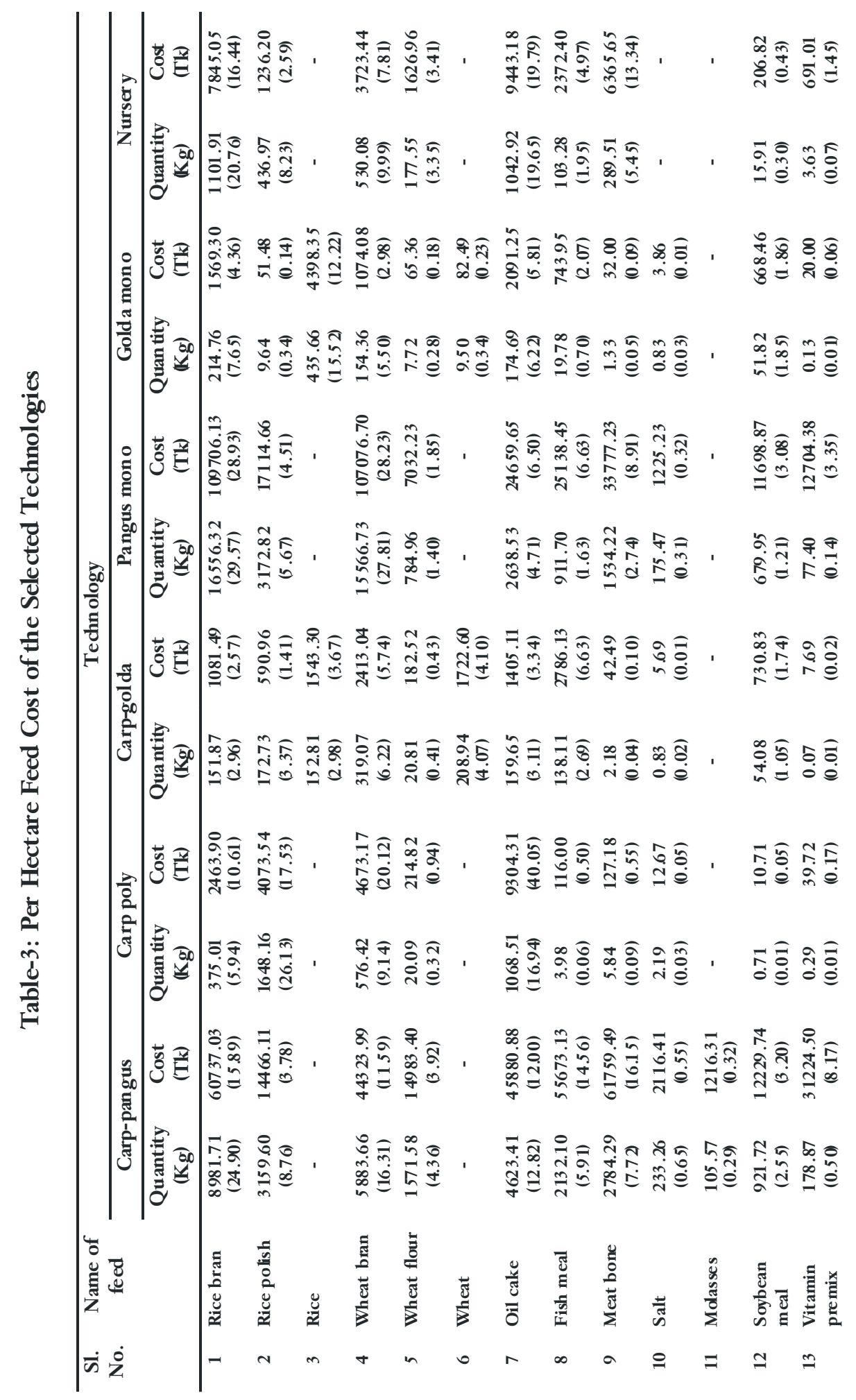




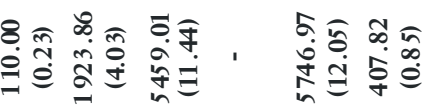

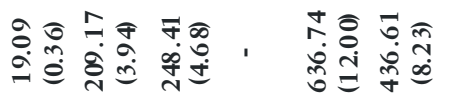

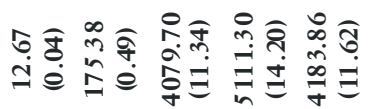

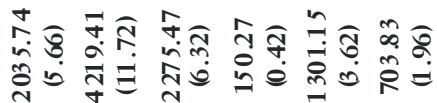

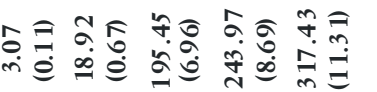

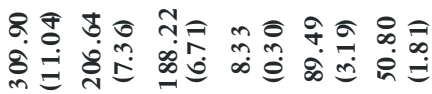

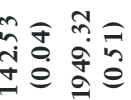

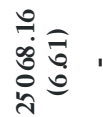

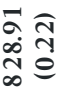

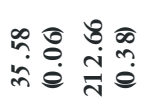

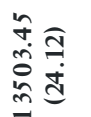

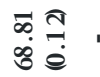

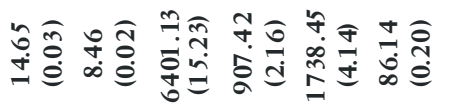

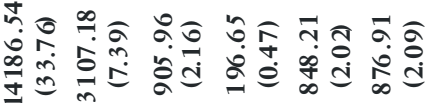

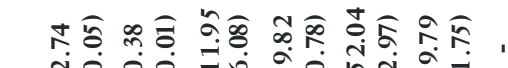

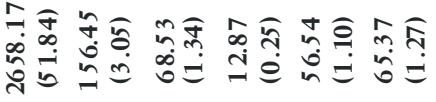

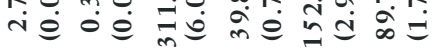

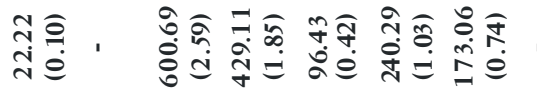

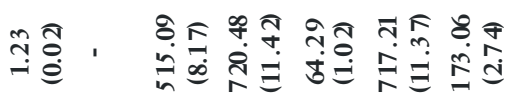

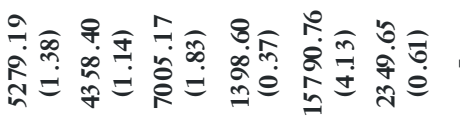

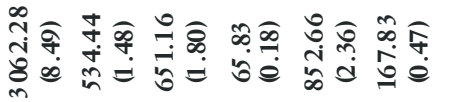

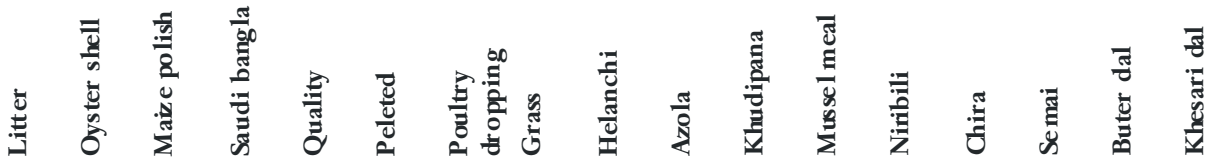

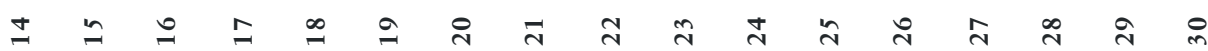




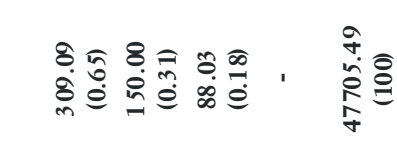

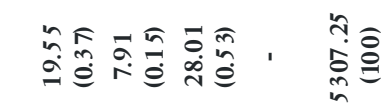

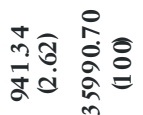

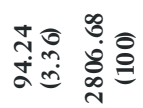

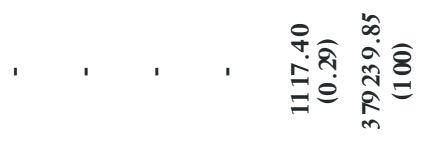

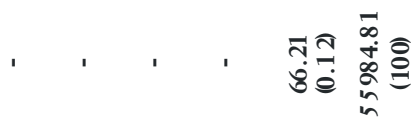

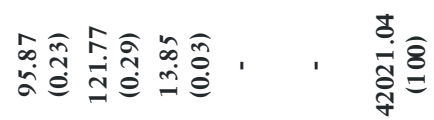

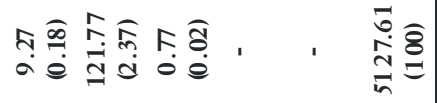

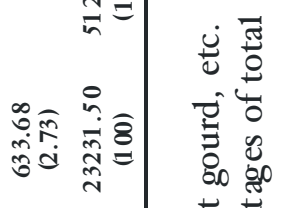

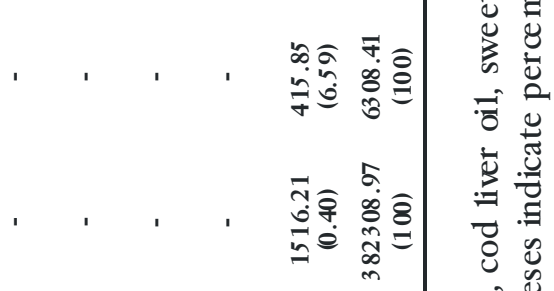

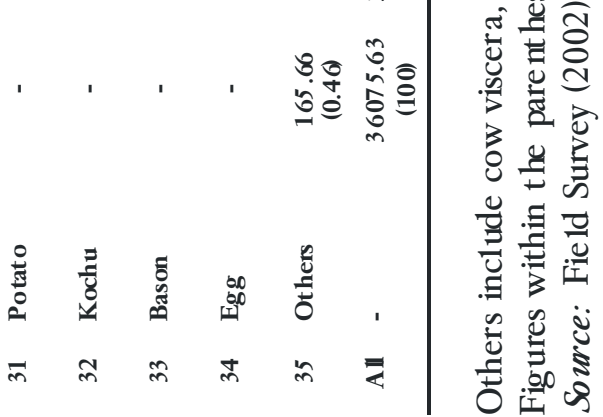


The most used five feed items for golda mono technology were rice (15.52 percent), peleted feed (11.31 percent), mussel meal (11.04 percent), quality feed $(8.69$ percent) and rice bran $(7.65$ percent $)$. On the other hand, the maximum expenditure incurred for five feed items of this technology were quality feed (14.20 percent), rice (12.22 percent), niribili (11.72 percent), peleted feed (11.62 percent) and saudi bangla (11.34 percent).

In the case of nursery technology, rice bran was the most important feed item ( 20.76 percent), followed by oil cake ( 19.65 percent), peleted feed (12.00 percent), wheat bran (9.99 percent) and rice polish and poultry dropping (each 8.23 percent). If expenditures for the feed items is considered, the five highest cost feed items were found to be oil cake (19.79 percent), rice bran (16.44 percent), meat bone (13.34 percent), peleted feed (12.05 percent) and saudi bangla (11.44 percent).

From above discussion it is clear that in terms of quantity used, rice bran appeared to be the largest feed item for carp-pangus, pangus mono and nursery technologies while rice polish, rice and mussel meal were the largest feed items for carp poly, golda mono and carp-golda technologies respectively. On the other hand, in terms of cost incurred, oil cake was found to be the major feed item for carp poly and nursery technologies while meat bone, mussel meal, rice bran and quality feed were major feed items for carp-pangus, carp-golda, pangus mono and golda mono technologies respectively.

\subsubsection{Other input cost of the selected technologies}

Inputs like fertilizer, manure, labour (human), machine, water and lease were considered as other inputs for the selected technologies for the present study. There were four types of fertilizer used by the selected technologies (Table-4). Among them carp-pangus, carp poly, carp-golda and nursery technologies used three types (urea, TSP and MP), pangus-mono used four types (urea, TSP, MP and zypsum) and golda mono used only two types (urea and TSP) of fertilizer. Except carp-golda, other technologies used urea more as compared to other fertilizers followed by TSP, MP and zypsum. Carp-golda technology used TSP the most followed by urea and MP. The only manure item, cow dung, was used by all the technologies and its quantity was greater than the quantities of fertilizers used. Lime was also used by all technologies and, except for carp-pangus, other technologies used poison for their culture operations. 
Human labor was used for pond preparation, intercultural operation and harvesting of fish from ponds. Machine charges and water costs were incurred for adding/irrigating water to the ponds. Moreover, the lease cost was the lease value of the pond area under operation.

In terms of cost incurred for using other inputs, labor for intercultural operation was the major cost item for all technologies except carp poly culture. The next largest input cost item for carp poly technology was labor for harvesting which constituted 36.20 percent of total other input cost. The second largest cost item was machine charge (22.16 percent) for carp-pangus technology while it was labor for intercultural operation for carp poly ( 25.67 percent), labor for harvesting for carp-golda (22.79 percent), golda mono ( 21.04 percent) and nursery (23.89 percent) and lease cost for pangus mono (17.46 percent) technologies. Moreover, Table-4 shows that machine charge and zipsum cost were the cost items experienced only by carp-pangus and pangus mono technologies respectively. 


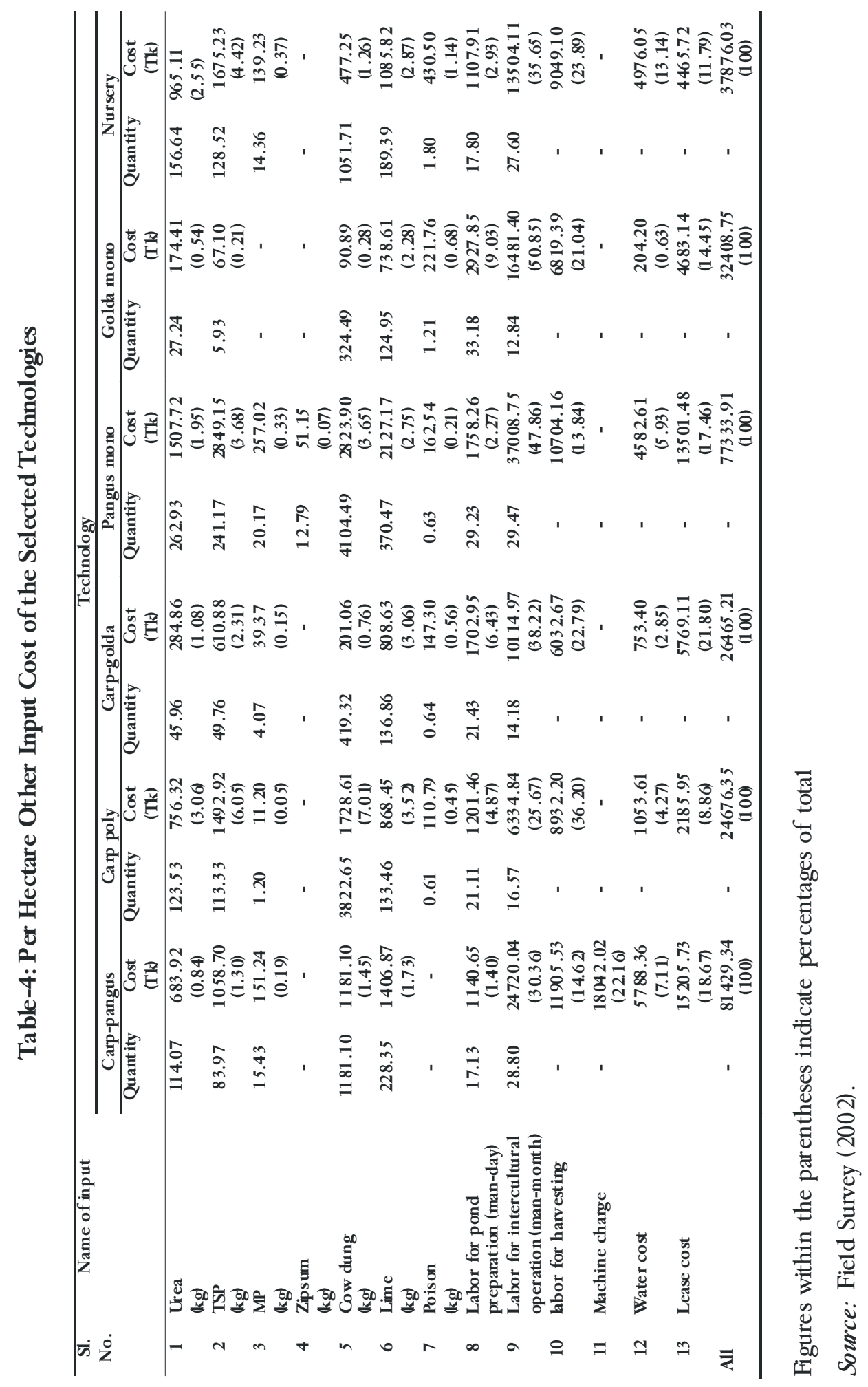




\subsubsection{Profitability of the selected technologies}

Total return was the value of fingerling harvested via the nursery technology while it was the value of fish harvested for other technologies. Table-5 indicates that the highest total return of Tk. 967530.24 was obtained in carp-pangus technology and was followed by pangus mono (Tk. 873758.67), nursery (Tk. 856954.55), carp-golda (Tk. 238654.66), golda mono (Tk. 231985.23) and carp poly (Tk. 166315.02) technologies.

Fingerling cost was the largest for pangus mono technology (Tk. 128602.30) and the second largest fingerling cost was experienced by the nursery technology (Tk. 118959.27). In terms of fingerling cost, these technologies were followed by carp-pangus (Tk. 95549.69), golda mono (Tk. 57505.26), carp-golda (Tk. 47936.23) and carp-poly (Tk. 12788.91).

Feed cost was found to be the highest for carp-pangus technology which was Tk. 382308.97 and it was followed by pangus mono, nursery, carp-golda, golda mono and carp poly technologies which had expenditures of Tk. 379239.85, 47705.49, 42021.04, 35990.70 and 23231.50 respectively. The ranking of the technologies for other input costs was carp-pangus, pangus mono, nursery, golda mono, carp-golda and carp poly with respective cost of Tk. 81429.34, 77333.91, 37876.03, $32408.75,26465.21$ and 24676.35 .

Total cost, comprising all cost items, was found to be the highest for pangus mono technology and it was Tk. 585176.06. It was followed by carp-pangus (Tk. 559288.00), nursery (Tk. 204540.79), golda mono (Tk. 125904.71), carp-golda (Tk. 116422.48) and carp poly (Tk. 60696.76) technologies under study.

Net return was derived by subtracting total cost from total return. It is evident from Table- 5 that the highest net return per hectare of Tk. 652413.74 was achieved by the nursery technology. The second highest net return technology was carp-pangus yielding a net return of Tk. 408242.24. The other technologies in terms of net return were pangus mono, carpgolda, golda mono and carp poly experiencing net returns of Tk. $288582.61,122232.18,106080.52$ and 105618.26 respectively. So, nursery was the most profitable technology followed by carp-pangus, pangus mono, carp-golda, golda mono and carp poly technologies. 


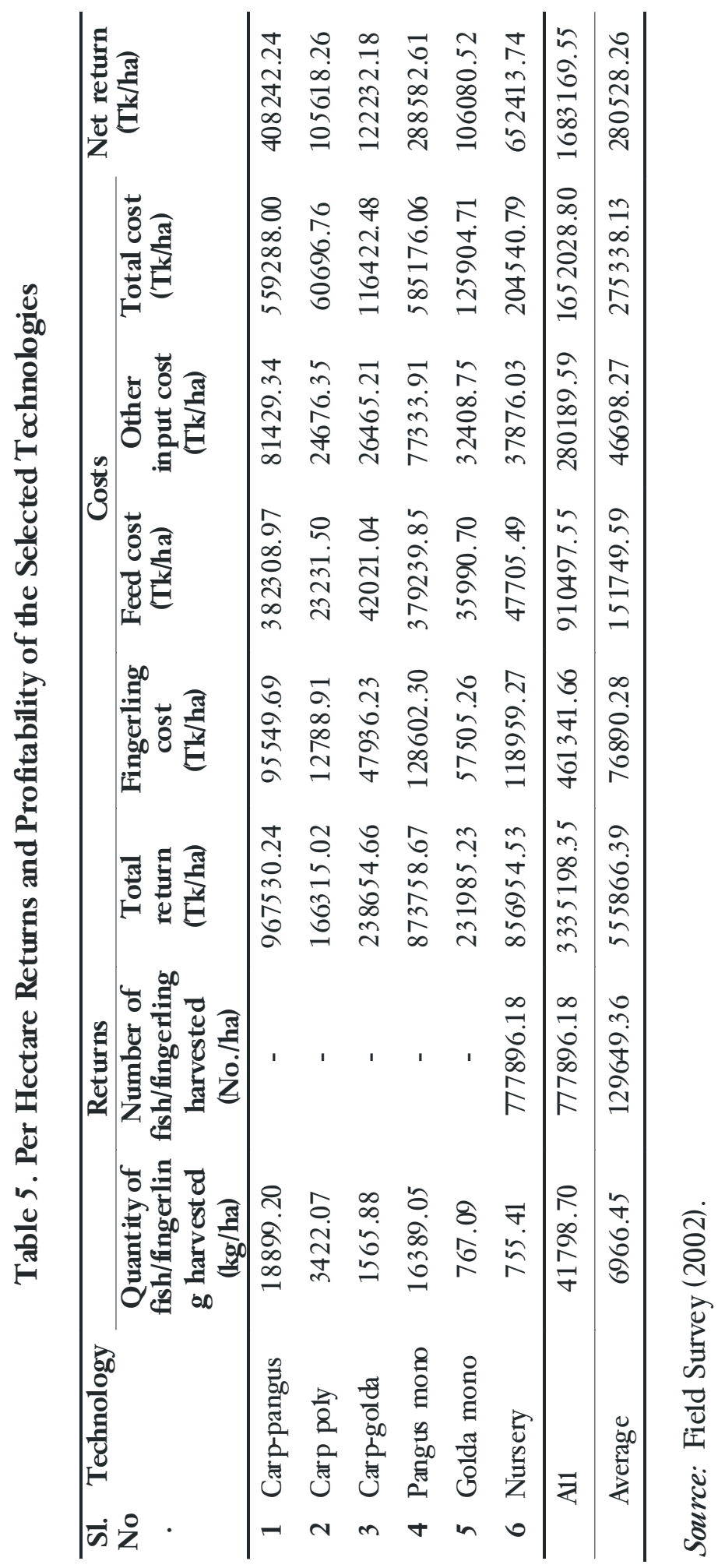




\subsection{Composition of Feed Items under Different Technologies}

In the study area, more than 35 feed items were used by the respondents using different technologies. Among them, the largest number of feeds (27) was used by carp-golga technology (Table-6). The second and third highest feed using technologies were golda mono (24) and carp-pangus (18) respectively. Each of the carp poly and nursery technologies used 17 feed items and ranked fourth while the lowest number of feeds (14) was used by pangus mono technology. So, carp-golda technology was the maximum feed-use technology and pangus mono technology was the minimum feed-use technology under study.

In terms of the frequency of the respondents and consideration of maximum used five feed items, wheat bran was the most commonly cited feed item by the carp-pangus respondents ( 90.91 percent), followed by oil cake ( 85.45 percent), rice bran ( 83.64 percent), vitamin premix $(67.27$ percent) and salt (61.82 percent). This ranking for carp poly technology was oil cake $(96.00$ percent), rice polish $(70.00$ percent), wheat bran $(56.00$ percent), grass (28 percent) and poultry dropping (23.00 percent). For carp-golda technology it was mussel meal (76.92 percent), oil cake (63.08 percent), wheat (46.79 percent), saudi bangla ( 46.15 percent) and wheat bran and rice bran (each of 43.08 percent). The ranking of the five common feed items for pangus mono technology was wheat bran, rice bran, oil cake, vitamin premix and salt having corresponding percentages of total respondents of 98.01, 96.08, 68.63, 62.75 and 56.86 percent. For golda mono technology, it was rice $(62.00$ percent), oil cake $(56.00$ percent), chira $(50.00$ percent), saudi bangla (40.00 percent) and niribili and semai (each of 34.00 percent).

Among the five feed items used by the largest number of nursery respondents, oil cake was the most common feed item (87.27 percent) followed by rice bran (49.09 percent), meat bone (43.64 percent), wheat flour ( 34.55 percent) and wheat bran $(32.73$ percent). So, rice was the most commonly used feed item by the respondents of golda mono technology, wheat bran for carp pangus and pangus mono technologies, oil cake for carp poly and nursery technologies and mussel meal for carp golda technology.

The last column of Table- 6 shows the frequency of technologies using different feed items for supplementary feed-based aquaculture in Bangladesh. It appears from the table that among 35 feed items, 9 items were used by all 6 technologies, followed by 3 items by 5 technologies, 4 items by 4 technologies, 2 items by 3 technologies, 9 items by 2 technologies and 8 items by 1 technology. The highest and most general nine feed items used by all technologies were rice bran, rice polish, wheat flour, wheat polish, oil cake, fish meal, meat bone, soybean meal and vitamin premix. 


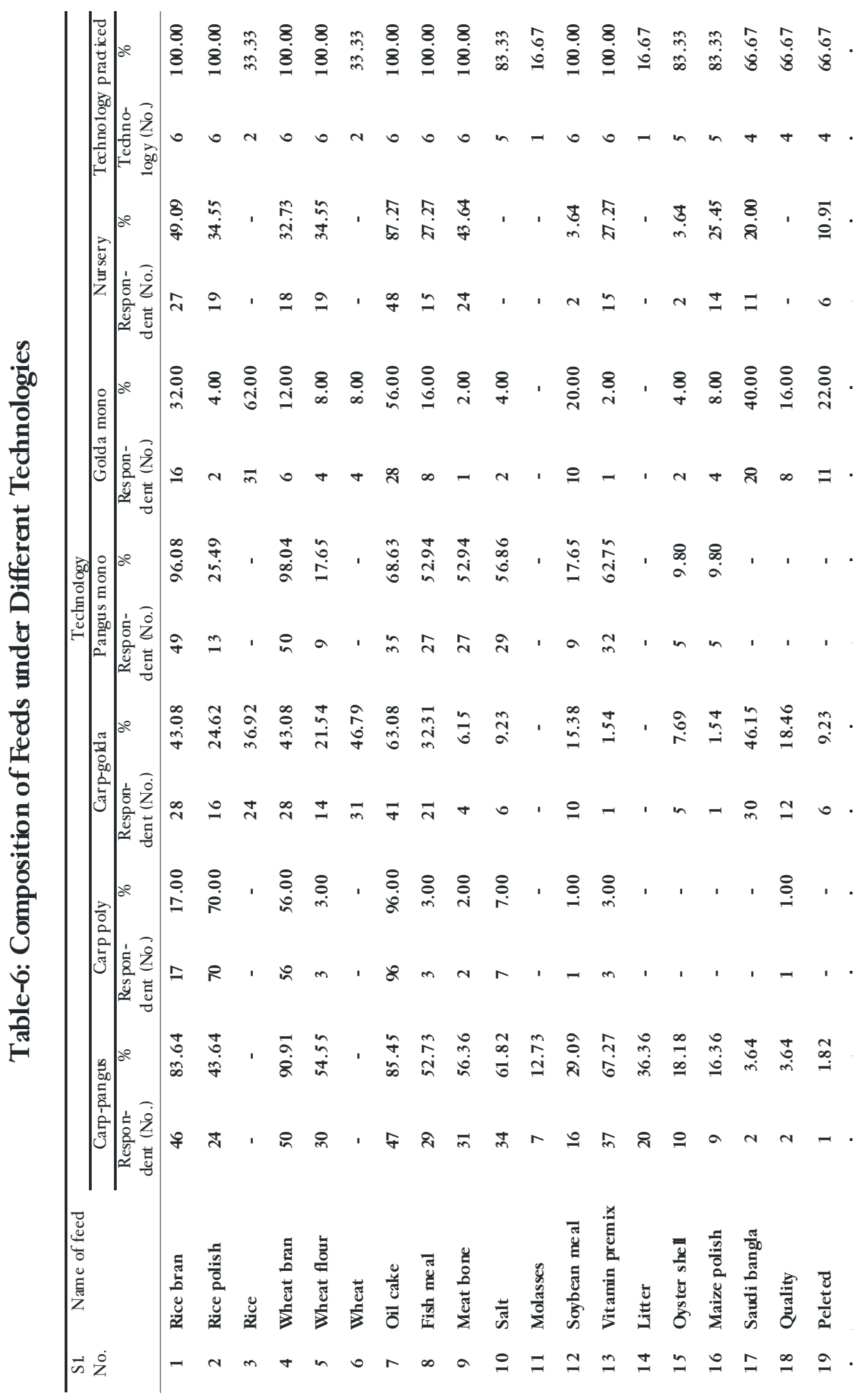




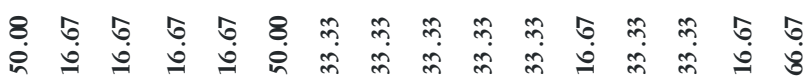

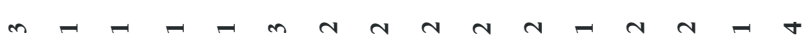

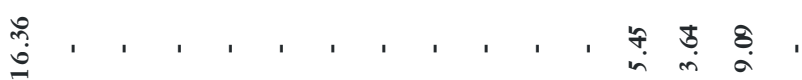

a $1,1,1,1,1,1,0 \mathrm{n}$,

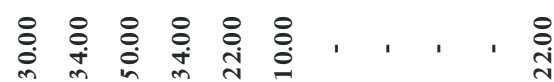

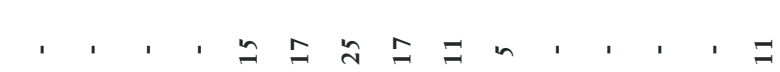

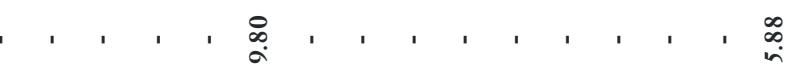

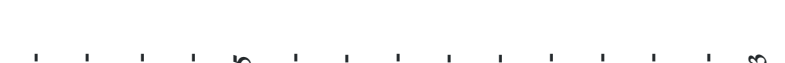

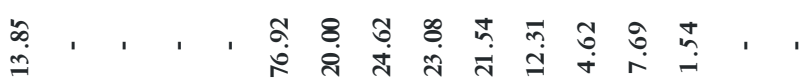

$\stackrel{u}{U}$

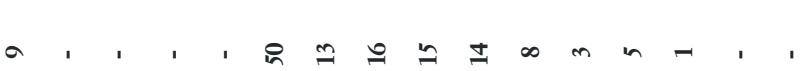

ఫొ

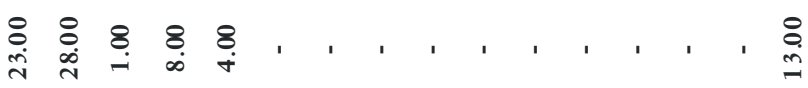

幽

$\approx \stackrel{\infty}{\infty}-\infty+1,1,1,1,1, \infty$

हैं

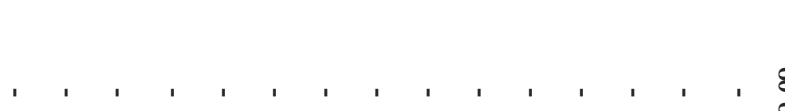

峁

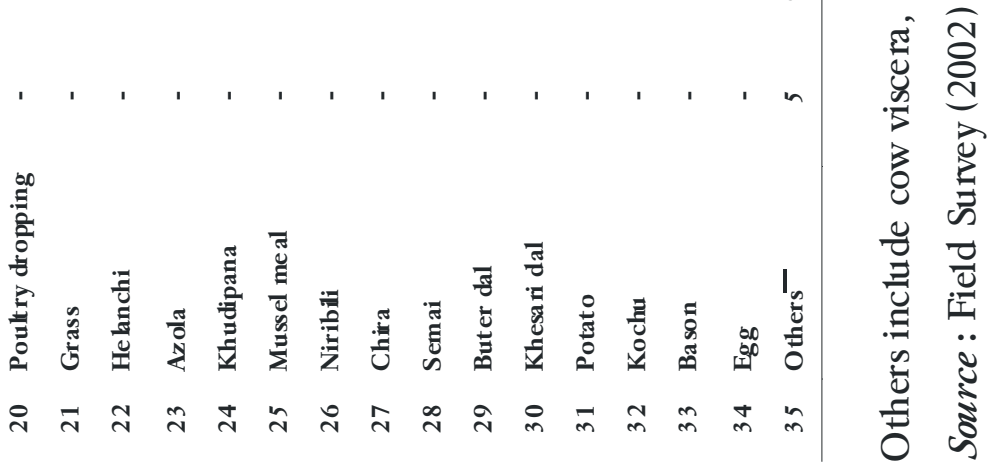




\subsection{Demand for Local Feed Items}

An attempt was made to determine the present demand for local feed items per hectare on the basis of the current pattern of feed use/requirement by the respondents under the selected technologies. Table7 reveals the requirement of six local feed items. Among them rice bran appeared with a maximum requirement of $8981.71,16556.32,214.76$ and $1101.91 \mathrm{~kg}$ per hectare for carp-pangus, pangus mono, golda mono and nursery technologies while rice polish $(1648.16 \mathrm{~kg})$ and wheat bran $(319.07$ $\mathrm{kg}$ ) were the largest requirement for carp poly and carp-golda technologies respectively. The table also reveals the average pond sizes of selected 6 technologies under study. The average pond sizes for carp-pangus, carp poly, carp-golda, pangus mono, golda mono and nursery technologies were found to be $0.32,0.26,0.64,0.36,0.60$ and 0.29 ha respectively. Thus the average pond size for all the technologies stood at 0.41 ha.

Table-7: Per Hectare Demand/Requirement of Local Feed Items

\begin{tabular}{|c|c|c|c|c|c|c|c|c|c|}
\hline \multirow{3}{*}{$\begin{array}{l}\text { S1. } \\
\text { No. }\end{array}$} & \multirow{3}{*}{ Feed item } & \multicolumn{8}{|c|}{ Technology } \\
\hline & & \multirow{2}{*}{$\begin{array}{c}\text { Carp- } \\
\text { pangus } \\
(\mathrm{kg})\end{array}$} & \multirow{2}{*}{$\begin{array}{l}\text { Carp } \\
\text { poly } \\
(\mathbf{k g})\end{array}$} & \multirow{2}{*}{$\begin{array}{c}\text { Carp- } \\
\text { golda } \\
(\mathrm{kg})\end{array}$} & \multirow{2}{*}{$\begin{array}{c}\text { Pangus } \\
\text { mono } \\
(\mathbf{k g})\end{array}$} & \multirow{2}{*}{$\begin{array}{c}\text { Golda } \\
\text { mono } \\
(\mathrm{kg})\end{array}$} & \multirow{2}{*}{$\begin{array}{c}\text { Nursery } \\
\text { (kg) }\end{array}$} & \multicolumn{2}{|c|}{ Average } \\
\hline & & & & & & & & $\mathbf{K g}$ & MT \\
\hline 1 & & 1 & 375.01 & 151.87 & 16556.32 & 214.76 & 1 & 456 & 4.56 \\
\hline 2 & INe & 3 & 16 & 172 & 317 & 9.64 & 43 & 1433.32 & 1.43 \\
\hline 3 & Wn & 588 & 576.42 & 319.07 & 1556 & 154.36 & & 3838.39 & 3.84 \\
\hline 4 & W & 1571.58 & 20.09 & 20.81 & 784.96 & 7.72 & 55 & 430.45 & 0.43 \\
\hline 5 & Oi1 & 46 & 106 & 15 & 26 & 174.69 & 10 & 161 & 1.62 \\
\hline 6 & Nrat & 651.16 & - & 0.38 & 212.66 & 18.92 & 209.17 & 182.05 & 0.18 \\
\hline Por & nd size (ha) & 0.32 & 0.26 & 0.64 & 0.36 & 0.60 & 0.29 & 0.41 & - \\
\hline
\end{tabular}

Source: Field Survey (2002).

Taking all technologies together, the average per hectare requirement of the local feed items, i.e., rice bran, rice polish, wheat bran, wheat flour, oil cake and maize polish amounted to $4.56,1.43,3.48,0.43$, 1.62 and 0.18 MT respectively. So, rice bran is the major feed item for feed based aquaculture in Bangladesh as its requirement was the highest (4.56 $\mathrm{MT} / \mathrm{ha}$ ) among all feed items. 


\subsection{Availability of Local Feed Items}

Different feed mills and companies were surveyed regarding the percentages of the above-mentioned six feed items (data on other feed items was not available) in the mother/original output/produce during the time of study. According to them, the overall percentages of rice bran, rice polish, wheat bran, wheat flour, oil cake and maize polish in mother/original output were estimated to be $2.08,22.50,14.00,3.50,63.50$ and 97.00 percent respectively. So, these percentages were multiplied with the respective original output to determine the availability of local feed items. Thus availability of local feed items appeared to be 479793.60, 5190075.00, 287973.00, $71993.25,172085.00$ and 3880.00 MT for rice bran, rice polish, wheat bran, wheat flour, oil cake and maize polish respectively.

Table-8: Availability of Local Feed Items

\begin{tabular}{|c|c|c|c|c|c|c|c|c|}
\hline \multirow{2}{*}{$\begin{array}{l}\text { Sl. } \\
\text { No. }\end{array}$} & \multicolumn{2}{|c|}{ Source } & \multicolumn{6}{|c|}{ Feed availability } \\
\hline & Name & Quantity & $\begin{array}{c}\text { Rice bran } \\
(2.08 \%) \\
\text { (MT) }\end{array}$ & $\begin{array}{c}\text { Rice polish } \\
(22.50 \%) \\
\text { (MT) }\end{array}$ & $\begin{array}{c}\text { Wheat } \\
\text { bran (14\%) } \\
\text { (MT) }\end{array}$ & $\begin{array}{c}\text { Wheat flour } \\
\text { (3.5\%) } \\
\text { (MT) }\end{array}$ & $\begin{array}{c}\text { Oil cake } \\
(63.5 \%) \\
(\mathrm{MT})\end{array}$ & $\begin{array}{l}\text { Maize polish } \\
\text { (97\%) } \\
\text { (MT) }\end{array}$ \\
\hline 1 & Rice & $\begin{array}{c}2306700 \\
0\end{array}$ & 479793.60 & 5190075.00 & - & - & - & - \\
\hline 2 & Wheat & 2056950 & - & - & 287973.00 & 71993.25 & - & - \\
\hline 3 & $\begin{array}{l}\text { Mustard } \\
\text { and Til }\end{array}$ & 271000 & - & - & - & - & 172085.00 & - \\
\hline 4 & Maize & 4000 & - & - & - & - & - & 3880.00 \\
\hline
\end{tabular}

Source: BBS (2004) and Field Survey (2002).

\subsection{Local Feed Prices}

An attempt was made to understand the movement of local feed prices for culture fisheries of the country. For this, draft documents of different feed companies were investigated. Remarkable variations were noted among the feed prices of different places. The average prices of local feed items for five years were collected which are shown in Table-9. The table indicates that the highest cost feed item was maize polish followed by wheat flour, oil cake, wheat bran, rice bran and rice polish. The corresponding prices per quintal for the year 1996 were found to be Tk. 695.00, 542.00, 389.00, 218.00, 211.00 and 111.00.

Figure 1 shows the three year moving average of price movements of the selected local feed items. It is evident from both the table and figure 
that local feed prices are increasing over time. Moreover, Figure 1 clearly shows that the rate of increase is going to be higher in succeeding years as feed based aquaculture incorporates more and more areas under its operation. So, proper steps (increasing land under feed production, introducing local feed processing technologies, extension services to the feed growers, etc.) need to be undertaken immediately to ensure the supply of local feeds to maintain feed prices within the purchasing ability of the fish farmers on one hand and make feed based aquaculture sustainable on the other.

Table-9: Local Feed Prices

\begin{tabular}{|c|c|c|c|c|c|c|c|c|c|c|c|}
\hline \multirow[t]{2}{*}{$\begin{array}{l}\text { Sl. } \\
\text { No. }\end{array}$} & \multirow[t]{2}{*}{ Feed item } & \multicolumn{5}{|c|}{ Price (Taka/quintal) } & \multicolumn{5}{|c|}{$\begin{array}{l}\text { Three yearly moving average } \\
\text { (Taka/quintal) }\end{array}$} \\
\hline & & 1996 & 1997 & 1998 & 1999 & 2000 & 1996 & 1997 & 1998 & 1999 & 2000 \\
\hline 1 & Rice & 211 & 258 & 343 & 479 & 682 & - & 270.67 & 360.00 & 501.33 & - \\
\hline 2 & Rice polish & 111 & 146 & 194 & 278 & 427 & - & 150.33 & 206.00 & 299.67 & - \\
\hline 3 & Wheat bran & 218 & 357 & 468 & 562 & 738 & - & 347.67 & 462.33 & 589.33 & - \\
\hline 4 & Wheat flour & 542 & 650 & 712 & 805 & 995 & - & 634.67 & 722.33 & 837.33 & - \\
\hline 5 & Oil cake & 389 & 495 & 610 & 714 & 917 & - & 498.00 & 606.33 & 747.00 & - \\
\hline 6 & Maize polish & 695 & 788 & 867 & 1035 & 1231 & - & 783.33 & 896.67 & 1044.33 & - \\
\hline
\end{tabular}

Source: Field Survey (2002) (unpublished documents of different feed companies).

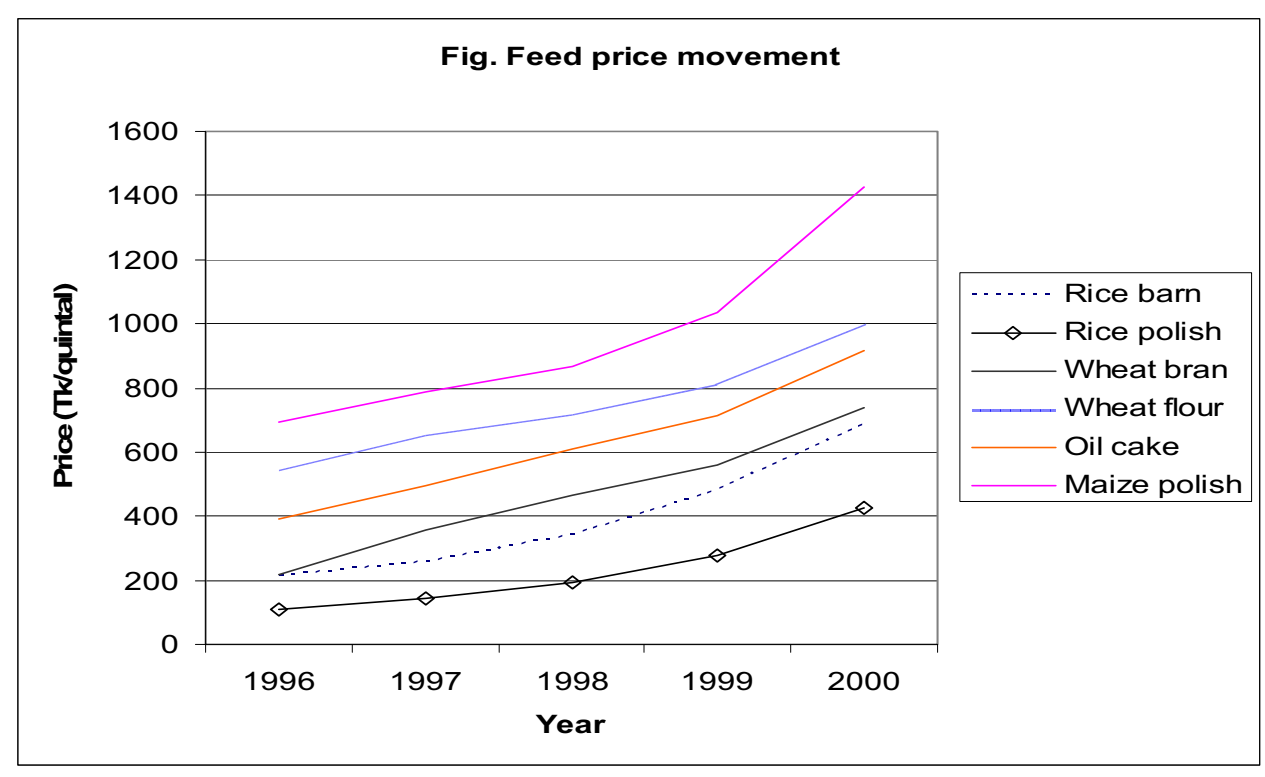




\subsection{Sustainability of Feed-based Aquaculture in Bangladesh}

Sustainability of feed based aquaculture with respect to local feed availability was studied. At present, the total pond and ditch area of Bangladesh is 305025 ha (DoF, 2005). Because of the absence of secondary data, senior officials and scientists of different research institutions were asked about the share of feed based aquaculture in the total pond and ditch area of Bangladesh. According to their responses, it was found that at least $75 \%$ of total pond and ditch area is currently under feed based aquaculture. Moreover, they stated that the area under feed based aquaculture is increasing day by day. The sustainability of feed based aquaculture is assessed in Table-10 with respect to $75 \%, 85 \%$ and $95 \%$ of total pond and ditch area of the country.

Table-10 clearly shows that, except rice polish, all five local feed items reveal a domestic production deficit irrespective of percentage of area under feed based aquaculture. Moreover, this deficit increases with the increase in area under operation. Among the deficits, the maximum deficit was associated with wheat bran $(590499.00 \mathrm{MT})$ followed by rice bran (563391.90 MT), oil cake (198520.38 MT), maize polish (37298.38 MT) and wheat flour (26377.38 MT) considering $75 \%$ of total area under feed-based aquaculture. These deficits are currently being met by importing feeds from abroad (importing the same feed items or other feeds to supplement the local feeds). As more and more area is being used for culture fisheries, the deficits are widening and feed based aquaculture is going to become a highly import dependent technology in Bangladesh. So, if this situation continues, feed based aquaculture will not be a sustainable income generating activity for the improvement of the livelihoods of the rural people of Bangladesh. 


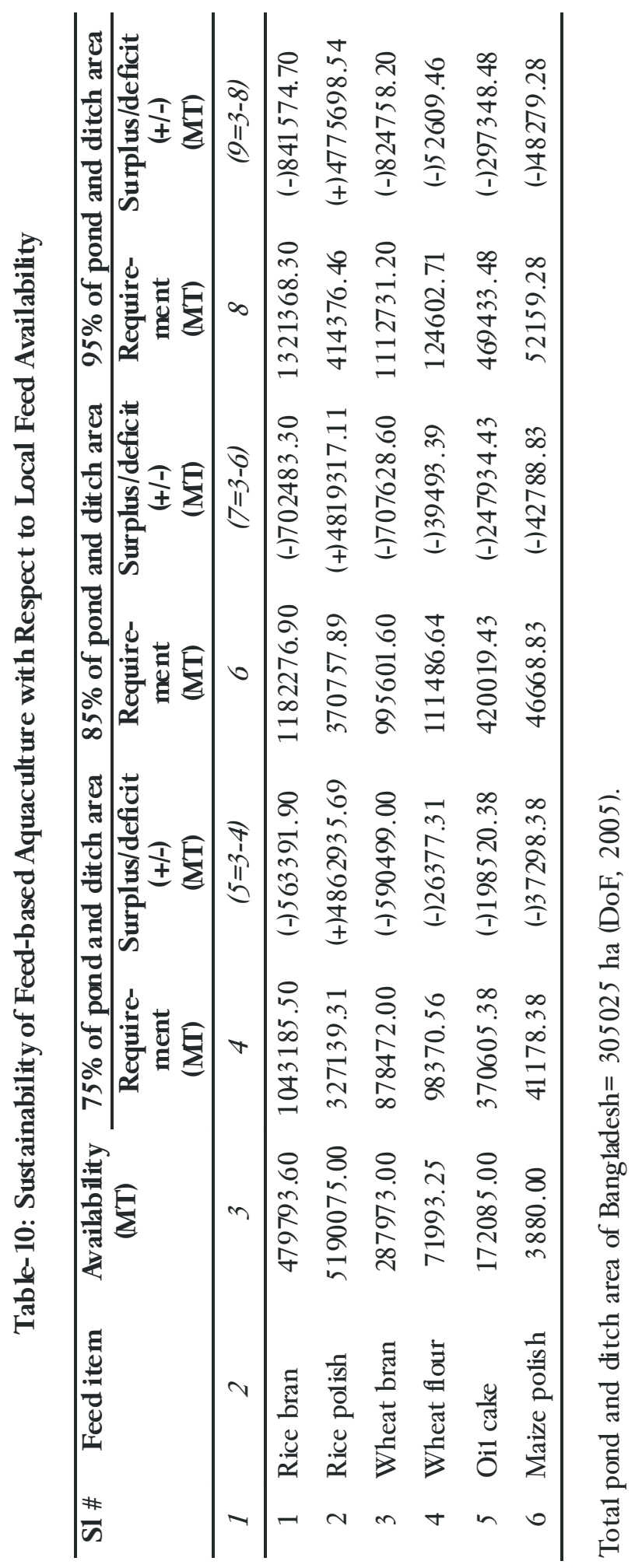




\section{Conclusion and Policy Implication}

\subsection{Conclusion}

The following conclusions can be drawn from the above study:

(i) Average pond sizes for the carp-pangus, carp poly, carp-golda, golda mono, pangus mono and nursery technologies were found to be $0.32,0.26,0.64,0.60,0.36$ and 0.29 ha respectively.

(ii) There were 14 types of fingerling used for the selected technologies. In the case of nurseries, fingerling was purchased both in weight and number basis.

(iii) More than 35 feed items were found to be used for the selected six technologies in different parts of the country. Among them were rice bran, rice polish, wheat bran, wheat flour, oil cake, fish meal, meat bone, soybean meal and vitamin premix- and these 9 feed items were used by all the technologies.

(iv) Among the local feed items, rice bran, rice polish, wheat bran, wheat flour, oil cake and maize polish were the most used feeds for the technologies under study.

(v) On average, per hectare feed requirements for the local feed items were estimated to be $4.56,1.43,3.84,0.43,1.62$ and 0.18 MT for rice bran, rice polish, wheat bran, wheat flour, oil cake and maize polish respectively.

(vi) Availability of local feed items mentioned above amounted to $479793.60,5190075.00,287973.00,71993.25,172085.00$ and 3880.00 MT respectively for the year 1999-2000.

(vii) On the basis of the above requirements and availability estimates, except rice polish, all the local feed items required imports to run culture fisheries in the country. As culture fisheries capture more and more areas under its operation, it is going to become an import dependent practice if the feed situation prevails without any measures to address it.

(viii) As culture fisheries are an important source of income and employment, they have a significant livelihood impact on the economy of Bangladesh. Therefore, proper policy and other measures 
are suggested to be taken by both the government organizations and NGOs to improve the local fish feed situation of the country.

\subsection{Policy Implications}

(i) BBS, DoF and other concerning organizations should record feed and other fisheries related data regularly.

(ii) The government and NGOs should come forward to establish local feed mills to cater to the feed requirement of the growing and promising fish culture industry.

(iii) Intensive research programs should be undertaken immediately by both GOs and NGOs for quality innovation.

(iv) Farmers/users should be trained so that they can use the feed and other inputs more efficiently.

(v) Capital should be supplied to the farmers who suffer from a lack of sufficient capital to use/purchase feeds from the market in a timely fashion.

(vi) A monitoring system should be developed to check the adulteration of fish feed in the country.

(vii) A subsidy/duty reduction package can be launched for imported feed ingredients (which cannot be produced domestically) so that supplementary fish culture can be sustained with lower costs of production.

\subsection{Livelihood Implications}

This project found a great livelihood impact of supplementary feedbased aquaculture in Bangladesh. This practice provides vast opportunities to the unemployed and self-employed rural youth of the country. Moreover, many people have already found ways to earn a living in feed processing and marketing. The nutritional and other values of supplementary fish culture are also worth mentioning. So, supplementary feed-based aquaculture should be made sustainable with local feed ingredients to explore its potential for poverty alleviation as well as economic development. 


\section{References}

BBS, 2000, Statistical Yearbook of Bangladesh, Bangladesh Bureau of Statistics, Ministry of Planning, Government of the Peoples' Republic of Bangladesh, Dhaka.

BBS, 2004, Statistical Yearbook of Bangladesh, Bangladesh Bureau of Statistics, Ministry of Planning, Government of the Peoples' Republic of Bangladesh, Dhaka.

Das, S., 2005, An Economic Study on Fingerling Production in Nursery Pond in Selected DSAP (Development of Sustainable Aquaculture Project) Areas of Bangladesh, M.S. Thesis, Department of Agricultural Economics, Bangladesh Agricultural University, Mymensingh-2202, Bangladesh.

DoF, 2005, Fisheries Statistical Yearbook of Bangladesh (2003-2004), Directorate of Fisheries, Dhaka, Bangladesh.

Hossain, M.A., Ahmed, M. and Islam, M.N., 1997, Mixed Culture of Fishes in Seasonal Ponds through Fertilization and Feeding, Bangladesh Journal of Fisheries Resources, 1(2):9-18.

Islam, M.S. and Dewan, S., 1986, Resource Use and Economic Return in Pond Fish Culture. Bangladesh Journal of Agricultural Economics, 9(2), 141-150.

Islam, M.S., 1987, An Economic Analysis of Pond Fish Production in Some Areas of Bangladesh, Research Report No. 11, Bureau of Socioeconomic Research and Training, Bangladesh Agricultural University, Mymensingh-2202, Bangladesh.

Islam, M.A., 2006, A Study on Economics of Fish Seed Production in Some Selected Areas of Bangladesh, M.S. Thesis, Department of Agricultural Economics, Bangladesh Agricultural University, Mymensingh-2202, Bangladesh.

Nurunnahar, M., 2005, Profitability and Resource Use Efficiency of Carp Fish Farms under Poly Culture Management: A Study in Some Selected Areas of Kushtia District of Bangladesh, M.S. Thesis, Department of Agricultural Economics, Bangladesh Agricultural University, Mymensingh-2202, Bangladesh. 
Puri, V.K., 1984, Fundamentals of Statistical Methods, Allied Publishers Private Limited, New Delhi, India.

Rahman, M.M., 1995, An Economic Study of Pond Fish Culture in Some Selected Areas of Mymensingh District. M.S. Thesis, Department of Agricultural Economics, Bangladesh Agricultural University, Mymensingh-2202, Bangladesh.

Rana, M.S., 1996, An Economic Analysis of Pond Fish Culture in Some Selected Areas of Sireajgonj District, M.S. Thesis, Department of Agricultural Economics, Bangladesh Agricultural University, Mymensingh-2202, Bangladesh. 
